\title{
Using economic-mathematical modeling in the study of the economic component of terrorism
}

\author{
Justin Dean \\ Manager Securities Services, Standard Chartered Bank, Pakistan \\ Olga Syniavska \\ Ph.D, Senior Lecturer, Sumy State University, Ukraine
}

Serhiy Minenko

Master's Degree Student, Sumy State University, Ukraine

\begin{abstract}
The article is devoted to the study of the dependence of the level of terrorism on the economic development of the country. The authors selected variables for the detection of dependencies, carried out a grouping on the level of economic development based on cluster analysis, constructed models of the dependence of the level of terrorism on the economic development of the country. The verification of the models for adequacy made it possible to conclude that constructed models can be used to predict the level of terrorism from countries similar to investigated countries in terms of economic development level.
\end{abstract}

Keywords: terrorism, terrorist attack, economic development, cluster analysis, regression, SAS.

JEL Classification: C32, C38, O11.

DOI: $10.21272 / \mathrm{sec} .1(2) .103-109.2017$.

(C) The Authors, 2017. This article is published with open access at ARMG Publishing.

\section{Introduction}

At the turn of the XX-XXI centuries, terrorism is ranked as one the most dangerous and difficult to predict phenomena, it is becoming increasingly diverse forms and threatening scales. At present, according to expert estimates, there are more than 500 terrorist organizations and groups of different orientations in the world. Geographically, the list covers the entire planet. For the first time, the issue of combating terrorism was passed to the UN summit on September 14-17, 2005. The reason for this were the tragic events of September 11, 2001 in the United States, Moscow in the Nord-Ost musical in October 2002, Beslan in September 2004, London Metro in July 2005, and instability that has a permanent character in the Middle East. Terrorists carry out violent acts of intimidation, directing the government to provide them with political or social concessions. Although bombs and bullets of terrorists are aimed at specific victims, their purpose is to intimidate a wider audience. There are also many cases where terrorists sought to cause negative economic consequences. This explains the negative socio-economic role of terrorism. According to the National Consortium for the Study of Terrorism and Responses to Terrorism (START), in 2016 Ukraine ranked 11th in terms of terrorism's impact on life in the country [11]. That is why the study of the impact of economic development on the level of terrorism is an urgent issue for Ukraine and for the whole world, which will give a deeper understanding the essence of the negative socio-economic impact of terrorism and the possibilities of research and prevention of terrorism.

\section{Literature review}

The issue of terrorism today is an extremely acute social issue. The connection between terrorism and economic, political, and social unrest is a topic of much interest. At the same time, many scientists study this phenomenon not as a social or political but as an economic one.

Thus, Josephine Cruz Lugovskyy in the paper "The Economic Determinants of Terrorism" indicated that there is a significant relationship between economic factors (such as country income, unemployment, and economic growth), social factors (such as population, income disparity, and political freedom), and the number of terrorist events worldwide [9]. These results imply that terrorist activity is indicative of larger 
problems with the economic and political fundamentals. Author analyzed the determinants of terror attacks using Hausman Taylor analysis, a panel estimation technique. As a result, she received that social parameters like education and democracy variables contribute more to terror than economic variables like income and employment rates.

A huge influence on the development of the research subject has scientists from Pakistan. In the recent history, Pakistan is facing the menace of terrorism. Besides facing the consequences of Afghan War, Pakistan is also affected by various ethnic, religious and linguistic conflicts which have increased terrorists' activities. These conflicts have severely affected the socio-economic structure of Pakistan.

For example, in the work "Imact of terrorism on economic development in Pakistan" by Shabir Hyder, Naeem Akram and Ihtsham Ul Haq Padda, to gauge the impact of terrorism on Pakistan's economic growth Solow economic growth model has been used [8]. Their analysis suggests that terrorism has negatively affected the economic growth in Pakistan. Among the various variables that were used the terrorism is most significant and major contributor in reducing the economic growth. However, study finds that foreign assistance that is provided to Pakistan in the aftermath of the participations in Afghan war and the war against terrorism; in the shape of aid, grants and debt rescheduling etc. has a positive impact on the economic growth.

Muhammad Shahbaz in his paper "Linkages between inflation, economic growth and terrorism in Pakistan" used ARDL bounds testing approach to cointegration [12]. Author concludes that an increase in inflation raises terrorist attacks while economic growth is also a major contributor to terrorism. Moreover, bidirectional causality is found between inflation and terrorism as investigated by the VECM Granger-causality approach while variance decomposition approach also supports the findings by the VECM Granger causality analysis.

Thomas Gries, Tim Kriegery and Daniel Meierrieksz in the paper "Causal Linkages Between Domestic Terrorism and Economic Growth" used Hsiao-Granger method to test for growth-terrorism causality for seven Western European countries [7]. They found that all investigated growth and terror series exhibit structural breaks matching major turning points in the countries' economic and political history. In bivariate systems, economic growth leads terrorist violence in all cases, whereas terrorism causally influences growth only for one country. They argued that economic performance appears to influence the terrorists' calculus,

while attacked economies are generally resistant to domestic terrorism. Authors noted that bivariate causality tests may be prone to inconsistencies, so they also performed causality tests in trivariate systems. The findings confirmed that economies under attack are successful in adjusting to the threats of terror, so economic growth is not impaired.

Raul Caruso investigated this processes in Europe. The main objective of his paper "The Socio-Economic Determinants of Terrorism and Political Violence in Western Europe" is to empirically investigate the socioeconomic causes of terrorism and political violence in a sample of 12 countries in Western Europe [4]. Received results are mixed. The results of his work show that expected future economic growth seems to be associated with an increase in current terrorist activities. The number of terrorist casualties is positively associated with real GDP per capita.

A study of the literature $[1,2,3,5,6,10]$ showed that scientists were studying the issue of the influence of terrorism on the level of the country's economic development, that is, terrorism was viewed as a cause, but not as a consequence. Accordingly, the issue of inverse connection between these processes has not been fully investigated.

That is why, the aim of this paper is to study the influence of the level of economic development of different countries on the number of terrorist attacks.

\section{Methodology}

To carry out a research, The Global Terrorism Database (GDT), which belongs to the National Consortium for the Study of Terrorism and Responses to Terrorism (START), has been used. It contains world-wide information on terrorist acts since 1970. A sample for the period 1991-2016 was generated from the database.

The level of terrorism is characterized by the number of terrorist acts committed per year. For the characteristics of economic development, the following indicators were taken by each country: gross domestic product (GDP, USD), exports of goods and services (\% of GDP), imports of goods and services (\% of GDP), 
inflation rate (GDP deflator, annual in \%), unemployment rate (in \% of the amount of labor force). These indicators are calculated by The World Bank and are open source [13].

The work is done using the SAS OnDemand for Academics software: SAS Enterprise Miner and SAS Guide.

To achieve the research goal, it was decided to use two tools of economic-mathematical modeling: cluster and regression analysis. By cluster analysis countries will be grouped into clusters based on selected indicators to form groups of countries with similar characteristics. With regression analysis, we obtain a mathematical description of the degree of terrorism's dependence on economic development for each group of countries.

\section{Results of the research}

The first stage of the research, as noted, was the cluster analysis. During the cluster analysis, the target variable was the name of the country, and the inputs were GDP, exports, imports, inflation, unemployment and the number of terrorist acts for 2016. Input data for cluster analysis is in Table 1.

Table 1. Input for cluster analysis

\begin{tabular}{|c|c|c|c|c|c|c|}
\hline Country & GDP & Unemployment & Inflation & Import & Export & $\begin{array}{c}\text { Number of } \\
\text { terrorist acts }\end{array}$ \\
\hline BGD & 173.00 & 4.30 & 5.66 & 25.52 & 18.98 & 130.00 \\
\hline CHN & 10400.00 & 4.70 & 0.81 & 21.57 & 24.08 & 37.00 \\
\hline COL & 378.00 & 10.10 & 2.13 & 21.35 & 15.96 & 230.00 \\
\hline DEU & 3870.00 & 5.00 & 1.73 & 39.12 & 45.65 & 13.00 \\
\hline DZA & 214.00 & 9.50 & -0.41 & 31.98 & 30.52 & 13.00 \\
\hline FRA & 2830.00 & 9.90 & 0.55 & 30.93 & 28.94 & 14.00 \\
\hline GBR & 2990.00 & 6.30 & 1.83 & 30.06 & 28.07 & 103.00 \\
\hline GRC & 236.00 & 26.30 & -2.20 & 34.93 & 32.50 & 26.00 \\
\hline IDN & 890.00 & 6.20 & 5.38 & 24.42 & 23.63 & 33.00 \\
\hline IND & 2040.00 & 3.60 & 3.29 & 25.88 & 22.91 & 860.00 \\
\hline ISR & 306.00 & 6.10 & 0.95 & 30.39 & 32.21 & 293.00 \\
\hline ITA & 2140.00 & 12.50 & 0.80 & 26.47 & 29.33 & 7.00 \\
\hline LBN & 46.00 & 6.40 & 1.27 & 69.35 & 57.49 & 204.00 \\
\hline LKA & 80.00 & 4.60 & 3.86 & 28.91 & 20.91 & 16.00 \\
\hline MEX & 1300.00 & 4.90 & 4.68 & 33.37 & 32.30 & 5.00 \\
\hline NGA & 568.00 & 7.50 & 4.66 & 12.45 & 18.43 & 713.00 \\
\hline PAK & 243.00 & 5.20 & 6.94 & 18.65 & 12.24 & 2147.00 \\
\hline PHL & 285.00 & 7.10 & 3.21 & 32.41 & 28.84 & 597.00 \\
\hline THA & 404.00 & 0.90 & 0.97 & 62.67 & 69.28 & 423.00 \\
\hline TUR & 799.00 & 9.20 & 8.27 & 32.12 & 27.88 & 90.00 \\
\hline USA & 17300.00 & 6.20 & 1.64 & 16.58 & 13.65 & 26.00 \\
\hline
\end{tabular}

Notes: BGD - Bangladesh, CHN - China, COL - Colombia, DEU - Germany, DZA - Algeria, FRA - France, GBR - United Kingdom, GRC - Greece, IDN - Indonesia, IND - India, ISR - Israel, ITA - Italy, LBN - Lebanon, LKA - Sri Lanka, MEX - Mexico, NGA - Nigeria, PAK - Pakistan, PHL - Philippines, THA - Thailand, TUR - Turkey, USA - United States.

The result of the cluster analysis was the distribution of the studied countries into three groups:

$1^{\text {st }}$ cluster: Bangladesh, Colombia, Algeria, Greece, Indonesia, India, Israel, Sri Lanka, Mexico, Nigeria,

Pakistan, Philippines, Turkey;

$>2^{\text {nd }}$ cluster: China, Germany, France, the United Kingdom, Italy, the USA;

$>3^{\text {rd }}$ cluster: Lebanon, Thailand.

Visual comparison of the size of the clusters is in Figure 1. 


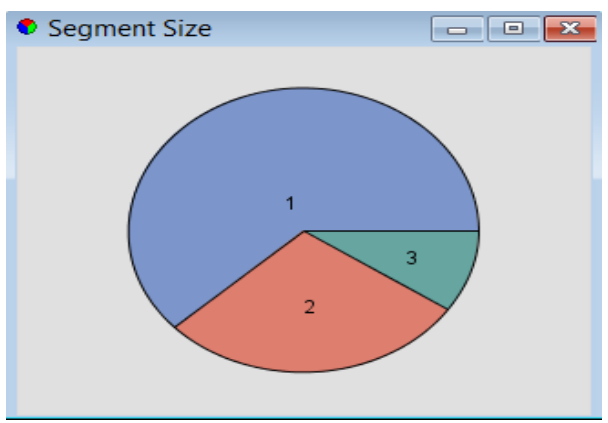

Figure 1. View of the "Segment Size" window of cluster analysis results

From the foregoing, it can be concluded that cluster analysis is adequately divided existing countries into groups. All countries in the clusters combine the similarity of the level of influence of terrorism on the country's life [11], the level of GDP and the level of inflation in the country.

The next step is constructing regression models for the selected clusters.

During a regression analysis, the target (dependent) variable is the average number of terrorist acts per corresponding cluster. and independent - the average GDP, exports. imports, inflation and unemployment by the corresponding cluster. Input data is pre-normalized, for a more understandable interpretation of the model and comparability of results. The input array includes GDP, exports, imports, inflation, unemployment and the number of terrorist acts per country. Using the Transform Variables block in the SAS package, we find average GDP, exports, imports, inflation, unemployment and the number of terrorist acts per country.

The construction of a model for the first cluster has the following parameters:

Polinomial Terms - yes;

Polinomial Degree - 2;

Regression Type - Linear Regression;

Correlation - yes;

Statistics - yes.

The regression equation for the $1^{\text {st }}$ cluster has the following form:

$$
\begin{aligned}
& \hat{y}_{1}=-0.926-1.384 \cdot x_{1}-0.492 \cdot x_{2}+2.847 \cdot x_{3}-0.613 \cdot x_{4}-0.184 \cdot x_{5}+8,756 \cdot x_{1}{ }^{2}+0.022 \cdot x_{1} \cdot x_{2}- \\
& 23.131 \cdot x_{1} \cdot x_{3}-1.097 \cdot x_{1} \cdot x_{4}-10.045 \cdot x_{1} \cdot x_{5}+0.692 \cdot x_{2}{ }^{2}-2.336 \cdot x_{2} \cdot x_{3}-0.374 \cdot x_{2} \cdot x_{4}- \\
& 0.996 \cdot x_{2} \cdot x_{5}+16.465 \cdot x_{3}{ }^{2}-2.175 \cdot x_{3} \cdot x_{4}+17.155 \cdot x_{3} \cdot x_{5}-1.454 \cdot x_{4}{ }^{2}-1.433 \cdot x_{4} \cdot x_{5}+3.265 \cdot x_{5}{ }^{2}
\end{aligned}
$$

where $y_{1}-$ the average number of terrorist acts for the $1^{\text {st }}$ cluster;

$x_{1}$ - the average value of exports of goods and services for the $1^{\text {st }}$ cluster;

$x_{2}$ - the average GDP for the $1^{\text {st }}$ cluster;

$x_{3}$ - the average value of import of goods and services for the $1^{\text {st }}$ cluster;

$x_{4}$ - the average value of inflation for the $1^{\text {st }}$ cluster;

$x_{5}$ - the average unemployment rate the $1^{\text {st }}$ cluster.

In order to analyze the quality of the constructed model we calculate the following indicators:

determination factor $\left(R^{2}\right)-84.40 \%$;

$>$ F-criterion -54.48 (the table value -2.77 );

$>$ standard deviation -0.03 .

These indicators mean that the constructed model is accurate and adequately describes the processes under investigation. A comparison of the theoretical (blue line) and actual (red line) values of the levels of the series is shown in Figure 2. 


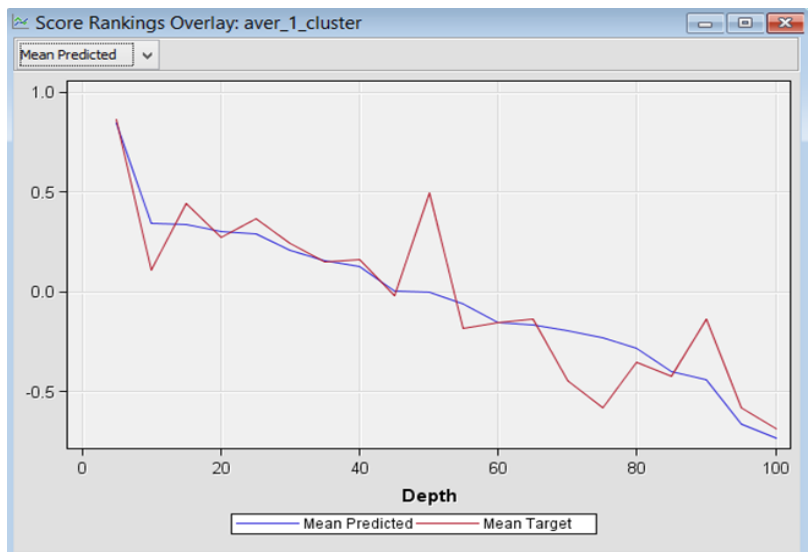

Figure 2. Actual and theoretical regression values for the $1^{\text {st }}$ cluster

Similarly, a regression for the second cluster was constructed:

$$
\begin{aligned}
& \hat{y}_{2}=-0.98-1.328 \cdot x_{1}+0.45 \cdot x_{2}+0.306 \cdot x_{3}-1.121 \cdot x_{4}+0.247 \cdot x_{5}+2.856 \cdot x_{1}{ }^{2}+0.312 \cdot x_{1} \cdot x_{2}- \\
& -3.539 \cdot x_{1} \cdot x_{3}+0.299 \cdot x_{1} \cdot x_{4}+1.829 \cdot x_{1} \cdot x_{5}-0.226 \cdot x_{2}{ }^{2}+0.739 \cdot x_{2} \cdot x_{3}+1.444 \cdot x_{2} \cdot x_{4}+ \\
& +1.549 \cdot x_{2} \cdot x_{5}+0.308 \cdot x_{3}{ }^{2}-2.049 \cdot x_{3} \cdot x_{4}-3.985 \cdot x_{3} \cdot x_{5}-0.18 \cdot x_{4}{ }^{2}+1.778 \cdot x_{4} \cdot x_{5}+1.358 \cdot x_{5}{ }^{2}
\end{aligned}
$$

where $y_{2}-$ the average number of terrorist acts for the $2^{\text {nd }}$ cluster;

$x_{1}$ - the average value of exports of goods and services for the $2^{\text {nd }}$ cluster;

$x_{2}$ - the average GDP for the $2^{\text {nd }}$ cluster;

$x_{3}$ - the average value of import of goods and services for the $2^{\text {nd }}$ cluster;

$x_{4}$ - the average value of inflation for the $2^{\text {nd }}$ cluster;

$x_{5}$ - the average unemployment rate the $2^{\text {nd }}$ cluster.

Analyzing the quality of the constructed model, we calculate the following indicators:

$>$ determination factor $\left(R^{2}\right)-97.90 \%$;

$>$ F-criterion -507.36 (the table value - 2.77);

$>$ standard deviation -0.01 .

These indicators mean that the constructed model is also accurate and adequately describes the processes under investigation. A comparison of the theoretical (blue line) and actual (red line) values of the levels of the series is shown in Figure 3.

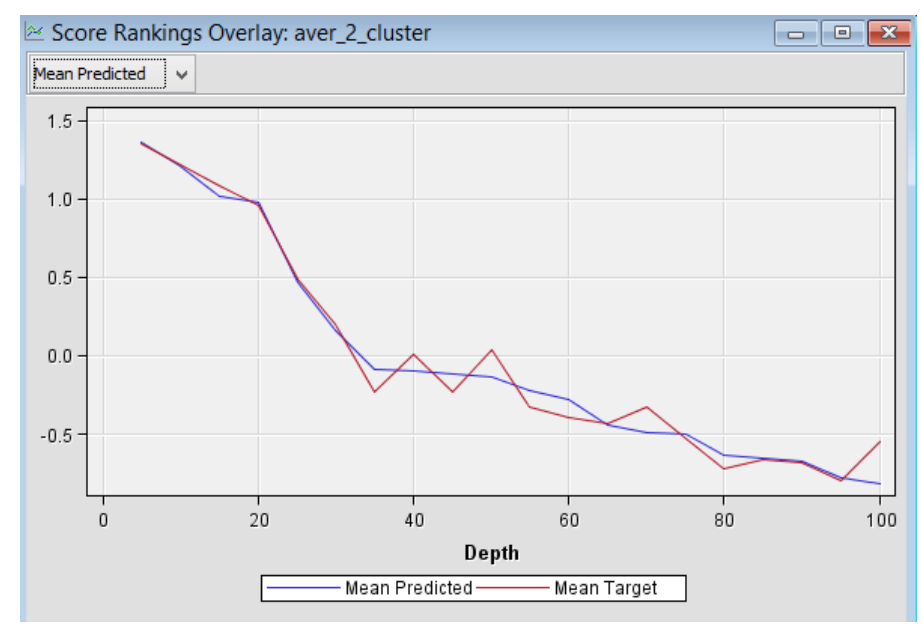

Figure 3. Actual and theoretical regression values for the $2^{\text {nd }}$ cluster

A regression for the last cluster is: 
$\hat{y}_{3}=-0.028-0.41 * x_{1}+1.175 * x_{2}+0.238 * x_{3}+0.293 * x_{4}+1.278 * x_{5}-2.958 * x_{1}^{2}+$

$+1.214 * x_{1} * x_{2}+6.354 * x_{1} * x_{3}-1.941 * x_{1} * x_{4}+0.723 * x_{1} * x_{5}+3.15 * x_{2}{ }^{2}-2.238 * x_{2} * x_{3}+$

$+0.97 * x_{2} * x_{4}+4.839 * x_{2} * x_{5}-3.797 * x_{3}^{2}+4.304 * x_{3} * x_{4}-2.664 * x_{3} * x_{5}-0.783 * x_{4}^{2}$

$+2.912 * x_{4} * x_{5}+1.193 * x_{5}^{2}$

where $y_{3}$ - the average number of terrorist acts for the $3^{\text {rd }}$ cluster;

$x_{1}$ - the average value of exports of goods and services for the $3^{\text {rd }}$ cluster;

$x_{2}$ - the average GDP for the $3^{\text {rd }}$ cluster;

$x_{3}$ - the average value of import of goods and services for the $3^{\text {rd }}$ cluster;

$x_{4}$ - the average value of inflation for the $3^{\text {rd }}$ cluster;

$x_{5}$ - the average unemployment rate the $3^{\text {rd }}$ cluster.

Analyzing the quality of the constructed model, we receive the following indicators:

$>$ determination factor $\left(R^{2}\right)-98.90 \%$;

$>$ F-criterion -983.53 (the table value - 2.77);

$>$ standard deviation -0.01 .

These indicators mean that the model for the third cluster is accurate and adequately describes the processes under investigation. A comparison of the theoretical (blue line) and actual (red line) values of the levels of the series is shown in Figure 4.

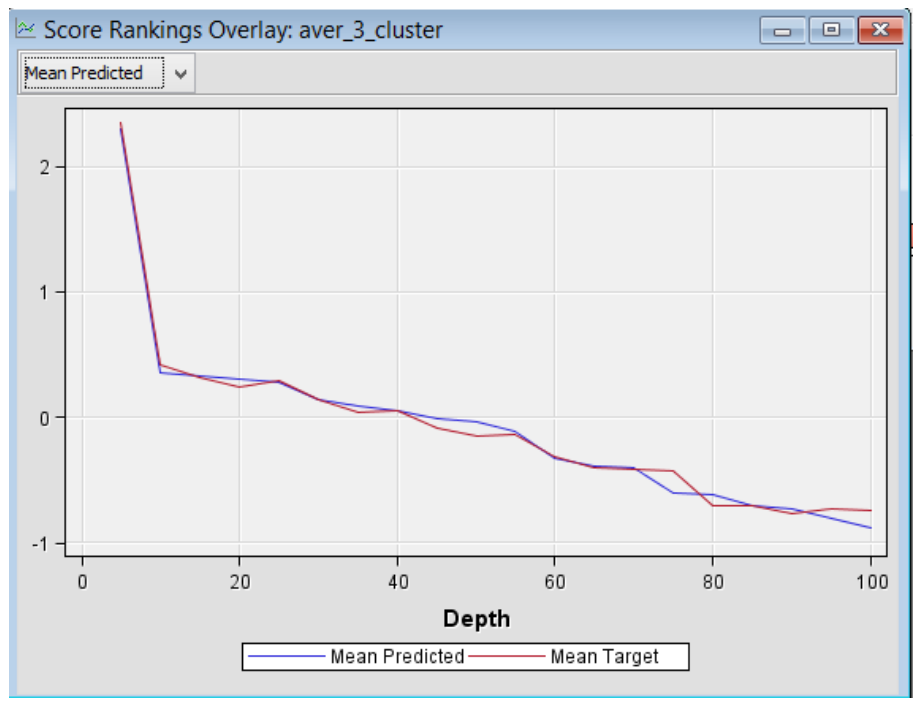

Figure 4. Actual and theoretical regression values for the $3^{\text {rd }}$ cluster

Using the constructed regression models makes it possible to forecast the number of terrorist attacks depending on the level of economic development in the studied countries. It is also possible to use these models for other countries, the level of economic development of which may be close to the level of the countries of the first, second or third cluster.

\section{Conclusions}

This paper has used data for constructing predictive regression models for three groups of countries that have similar features in the economic development and in activity of terrorist groups.

During the investigation, a representative sample of data on the economic development of the world and the activity of terrorist groups was created, received data was grouped on the basis of common features through cluster analysis and the impact of economic development on the level of terrorism in the countries was analyzed. 
According to the investigation, it is safe to say that there is a link between the level of economic development and terrorism. Moreover, some factors, that characterize economic development, contribute to the decreasing of terrorism, while others, on the contrary, increasing.

The constructed models have both theoretical and practical value for combating terrorism. Based on these models, it is possible to predict the level of terrorism in countries that have similar economic development to the investigated countries and to plan measures to prevent terrorism.

\section{References}

1. Abadie, A., Gardeazabal, J. (2008). Terrorism and the World Economy. European Economic Review, 52, $1-27$.

2. Blomberg, S.B. and Hess, G.D. (2008) From (No) Butter to Guns? Understanding the Economic Role in Transnational Terrorism. Terrorism, Economic Development, and Political Openness, edited by P. Keefer and N. Loyaza, New York: Cambridge University Press, 83-115.

3. Blomberg, S.B., Hess, G.D. and Weerapana, A. (2004). Economic conditions and terrorism. European Journal of Political Economy, 20, 463-478.

4. Caruso, R. (2010). The Socio-Economic Determinants of Terrorism and Political Violence in Western Europe. European Journal of Political Economy, 27(1), 37-49.

5. Eckstein, Z. and Tsiddon, D. (2004). Macroeconomic consequences of terror: theory and the case of Israel. Journal of Monetary Economics, 51, 971-1002.

6. Gaibulloev, K. and Sandler, T. (2008). Growth Consequences of Terrorism in Western Europe. Kyklos 61(3), 411-424.

7. Gries T., Kriegery, T., Meierrieksz, D. (2009). Causal Linkages Between Domestic Terrorism and Economic Growth. Center for International Economics Working Paper Series, 2, 23 p.

8. Hyder, S., Akram, N., Padda I. (2015) Imact of terrorism on economic development in Pakistan. Pakistan business review 2015, 704-722.

9. Lugovskyy, J. (2014). The Economic Determinants of Terrorism. International Journal of the Academic Business World, 8(2), 51-62.

10.Nasir, M., Ali, A., Rehman, F. (2011). Determinants of terrorism: a panel data analysis of selected South Asian countries. Singapore Economic Review 56 (02), 145-162.

11.National Consortium for the Study of Terrorism and Responses to Terrorism (START). http://economicsandpeace.org/wp-content/uploads/2016/11/GlobalTerrorism-Index-2016.2.pdf. Accessed 15 October 2016.

12.Shahbaz, M. (2013) Linkages between inflation, economic growth and terrorism in Pakistan. Economic Modelling, 32, 496-506.

13.The World bank. Indicators. http://data.worldbank.org/indicator. Accessed 15 October 2016. 